\title{
Common fixed points of $g$-quasicontractions and related mappings in 0-complete partial metric spaces
}

Cristina di Bari ${ }^{1}$, Zoran Kadelburg${ }^{2}$, Hemant Kumar Nashine ${ }^{3}$ and Stojan Radenovićc ${ }^{*}$

\section{"Correspondence:}

radens@beotel.net

${ }^{4}$ Faculty of Mechanical Engineering,

University of Belgrade, Kraljice

Marije 16, Beograd, 11120, Serbia

Full list of author information is

available at the end of the article

\begin{abstract}
Common fixed point results are obtained in 0-complete partial metric spaces under various contractive conditions, including g-quasicontractions and mappings with a contractive iterate. In this way, several results obtained recently are generalized. Examples are provided when these results can be applied and neither corresponding metric results nor the results with the standard completeness assumption of the underlying partial metric space can.
\end{abstract}

MSC: $47 \mathrm{H} 10 ; 54 \mathrm{H} 25$

Keywords: fixed point; common fixed point; partial metric space; 0-complete space; quasicontraction

\section{Introduction and preliminaries}

Matthews [15] introduced the notion of a partial metric space as a part of the study of denotational semantics of dataflow networks. He showed that the Banach contraction mapping theorem can be generalized to the partial metric context for applications in program verification. Subsequently, several authors (see, e.g., [1-3, 6, 8, 12-14, 16, 17, 20, 22]) derived fixed point theorems in partial metric spaces. See also the presentation by Bukatin et al. [4] where the motivation for introducing non-zero distance (i.e., the 'distance' $p$ where $p(x, x)=0$ need not hold) is explained, which is also leading to interesting research in foundations of topology.

The following definitions and details can be seen, e.g., in $[3,4,11,15,16,21]$.

Definition 1 A partial metric on a nonempty set $X$ is a function $p: X \times X \rightarrow \mathbb{R}^{+}$such that for all $x, y, z \in X$ :

$\left(\mathrm{p}_{1}\right) x=y \Longleftrightarrow p(x, x)=p(x, y)=p(y, y)$,

$\left(\mathrm{p}_{2}\right) p(x, x) \leq p(x, y)$,

( $\left.\mathrm{p}_{3}\right) p(x, y)=p(y, x)$,

$\left(\mathrm{p}_{4}\right) p(x, y) \leq p(x, z)+p(z, y)-p(z, z)$.

The pair $(X, p)$ is called a partial metric on $X$.

It is clear that, if $p(x, y)=0$, then from $\left(\mathrm{p}_{1}\right)$ and $\left(\mathrm{p}_{2}\right) x=y$. But if $x=y, p(x, y)$ may not be 0 .

(c) 2012 di Bari et al.; licensee Springer. This is an Open Access article distributed under the terms of the Creative Commons Attribution License (http://creativecommons.org/licenses/by/2.0), which permits unrestricted use, distribution, and reproduction in any medium, provided the original work is properly cited. 
Each partial metric $p$ on $X$ generates a $T_{0}$ topology $\tau_{p}$ on $X$ which has as a base the family of open $p$-balls $\left\{B_{p}(x, \varepsilon): x \in X, \varepsilon>0\right\}$, where $B_{p}(x, \varepsilon)=\{y \in X: p(x, y)<p(x, x)+\varepsilon\}$ for all $x \in X$ and $\varepsilon>0$. A sequence $\left\{x_{n}\right\}$ in $(X, p)$ converges to a point $x \in X$ (in the sense of $\left.\tau_{p}\right)$ if $\lim _{n \rightarrow \infty} p\left(x, x_{n}\right)=p(x, x)$. This will be denoted as $x_{n} \rightarrow x(n \rightarrow \infty)$ or $\lim _{n \rightarrow \infty} x_{n}=x$.

If $T: X \rightarrow X$ is continuous at $x_{0} \in X$ (with respect to $\tau_{p}$ ), then for each sequence $\left\{x_{n}\right\}$ in $X$, we have

$$
x_{n} \rightarrow x_{0} \quad \Rightarrow \quad T x_{n} \rightarrow T x_{0}
$$

Remark 1 Clearly, a limit of a sequence in a partial metric space need not be unique. Moreover, the function $p(\cdot, \cdot)$ need not be continuous in the sense that $x_{n} \rightarrow x$ and $y_{n} \rightarrow y$ imply $p\left(x_{n}, y_{n}\right) \rightarrow p(x, y)$.

If $p$ is a partial metric on $X$, then the function $p^{s}: X \times X \rightarrow \mathbb{R}^{+}$given by

$$
p^{s}(x, y)=2 p(x, y)-p(x, x)-p(y, y)
$$

is a metric on $X$. Furthermore, $\lim _{n \rightarrow \infty} p^{s}\left(x_{n}, x\right)=0$ if and only if

$$
p(x, x)=\lim _{n \rightarrow \infty} p\left(x_{n}, x\right)=\lim _{n, m \rightarrow \infty} p\left(x_{n}, x_{m}\right) .
$$

\section{Example 1}

(1) A paradigmatic example of a partial metric space is the pair $\left(\mathbb{R}^{+}, p\right)$, where $p(x, y)=\max \{x, y\}$ for all $x, y \in \mathbb{R}^{+}$. The corresponding metric is

$$
p^{s}(x, y)=2 \max \{x, y\}-x-y=|x-y|
$$

(2) If $(X, d)$ is a metric space and $c \geq 0$ is arbitrary, then

$$
p(x, y)=d(x, y)+c
$$

defines a partial metric on $X$ and the corresponding metric is $p^{s}(x, y)=2 d(x, y)$.

Other examples of partial metric spaces which are interesting from a computational point of view may be found in $[9,15]$.

Definition 2 Let $(X, p)$ be a partial metric space. Then:

1. A sequence $\left\{x_{n}\right\}$ in $(X, p)$ is called a Cauchy sequence if $\lim _{n, m \rightarrow \infty} p\left(x_{n}, x_{m}\right)$ exists (and is finite).

2. The space $(X, p)$ is said to be complete if every Cauchy sequence $\left\{x_{n}\right\}$ in $X$ converges, with respect to $\tau_{p}$, to a point $x \in X$ such that $p(x, x)=\lim _{n, m \rightarrow \infty} p\left(x_{n}, x_{m}\right)$.

3. [18] a sequence $\left\{x_{n}\right\}$ in $(X, p)$ is called 0 -Cauchy if $\lim _{n, m \rightarrow \infty} p\left(x_{n}, x_{m}\right)=0$. The space $(X, p)$ is said to be 0 -complete if every 0 -Cauchy sequence in $X$ converges (in $\left.\tau_{p}\right)$ to a point $x \in X$ such that $p(x, x)=0$. 
Lemma 1 Let $(X, p)$ be a partial metric space.

(a) $\left\{x_{n}\right\}$ is a Cauchy sequence in $(X, p)$ if and only if it is a Cauchy sequence in the metric $\operatorname{space}\left(X, p^{s}\right)$.

(b) The space $(X, p)$ is complete if and only if the metric space $\left(X, p^{s}\right)$ is complete.

(c) Every 0-Cauchy sequence in $(X, p)$ is Cauchy in $\left(X, p^{s}\right)$.

(d) If $(X, p)$ is complete, then it is 0 -complete.

The converse assertions of (c) and (d) do not hold as the following easy example shows.

Example 2 ([18]) The space $X=[0,+\infty) \cap \mathbb{Q}$ with the partial metric $p(x, y)=\max \{x, y\}$ is 0 -complete, but is not complete (since $p^{s}(x, y)=|x-y|$ and $\left(X, p^{s}\right)$ is not complete). Moreover, the sequence $\left\{x_{n}\right\}$ with $x_{n}=1$ for each $n \in \mathbb{N}$ is a Cauchy sequence in $(X, p)$, but it is not a 0 -Cauchy sequence.

Recall that Romaguera proved in [18, Theorem 2.3] that a partial metric space $(X, p)$ is 0 -complete if and only if every $p^{s}$-Caristi mapping on $X$ has a fixed point.

It is easy to see that every closed subset of a 0 -complete partial metric space is 0 complete.

Let $(X, p)$ be a partial metric space and $f, g: X \rightarrow X$ be two selfmaps. When constructing various contractive conditions, usually one of the following sets is used:

$$
\begin{aligned}
& M_{f, g}^{5}(x, y)=\{p(g x, g y), p(g x, f x), p(g y, f y), p(g x, f y), p(g y, f x)\}, \\
& M_{f, g}^{4}(x, y)=\left\{p(g x, g y), p(g x, f x), p(g y, f y), \frac{1}{2}(p(g x, f y)+p(g y, f x))\right\}, \\
& M_{f, g}^{3}(x, y)=\left\{p(g x, g y), \frac{1}{2}(p(g x, f x)+p(g y, f y)), \frac{1}{2}(p(g x, f y)+p(g y, f x))\right\} .
\end{aligned}
$$

Then, the contractive condition takes the form

$$
p(f x, f y) \leq \lambda \max M_{f, g}^{i}(x, y),
$$

where $\lambda \in[0,1)$. Mappings $f$ satisfying (1.2) with $i=5$ for all $x, y \in X$ (in metric case) are usually called $g$-quasicontractions (see Ćirić [5] and Das and Naik [7]).

(Common) fixed point results in partial metric spaces using conditions of mentioned type in the case $i=3,4$ were obtained in various papers. We prove in Section 2 a common fixed point theorem for $g$-quasicontractions in 0 -complete spaces that contains as special cases several other results. In Section 3 a partial metric extension of Sehgal-Guseman result for mappings having a contractive iterate is obtained. Finally, in Section 4 we deduce a partial metric version of (common) fixed point theorem under the condition [17, (19)] of B. E. Rhoades.

Examples are provided when these results can be applied and neither corresponding metric results nor the results with the standard completeness assumption of the underlying partial metric space can.

\section{Quasicontractions in partial metric spaces}

Theorem 1 Let $(X, p)$ be a 0 -complete partial metric space and let $f, g: X \rightarrow X$ be two selfmaps such that $f X \subset g X$, and one of these two subsets of $X$ is closed. If there exists $\lambda \in$ 
$[0,1)$ such that the condition

$$
p(f x, f y) \leq \lambda \max M_{f, g}^{5}(x, y)
$$

holds for all $x, y \in X$, where

$$
M_{f, g}^{5}(x, y)=\{p(g x, g y), p(g x, f x), p(g y, f y), p(g x, f y), p(g y, f x)\},
$$

then $f$ and $g$ have a unique point of coincidence. If, moreover, $f$ and $g$ are weakly compatible, then they have a unique common fixed point $u$ such that $p(u, u)=0=p(f u, f u)$.

Recall that $x \in X$ is called a coincidence point of $f, g: X \rightarrow X$ and $y$ is their point of coincidence if $f x=g x=y$. If $f$ and $g$ commute at their coincidence points, they are called weakly compatible.

Proof For arbitrary $x_{0} \in X$, and using that $f X \subset g X$, choose a Jungck sequence $\left\{y_{n}\right\}$ in $X$ by

$$
y_{n}=f x_{n}=g x_{n+1}, \quad n \in \mathbb{N}_{0} .
$$

Denote by $O_{f, g}\left(x_{0} ; n\right)=\left\{y_{0}, y_{1}, \ldots, y_{n}\right\}$ the $n$th orbit of $x_{0}$ and by $O_{f, g}\left(x_{0} ; \infty\right)=\left\{y_{0}, y_{1}, y_{2}, \ldots\right\}$ its orbit. Also, denote by $\operatorname{diam} A=\sup \{p(x, y) \mid x, y \in A\}$ the diameter of a nonempty set $A \subset X$. Note that $\operatorname{diam} A=0$ implies that $A$ is a singleton, but the converse is not true.

If $p\left(y_{n}, y_{n+1}\right)=0$ for some $n \in \mathbb{N}_{0}$, then it is easy to prove (using properties $\left(\mathrm{p}_{2}\right)$ and $\left(\mathrm{p}_{4}\right)$ of the partial metric, and the contractive condition (2.1)) that $p\left(y_{n+1}, y_{n+2}\right)=0$, i.e., $y_{n}=y_{n+1}=y_{n+2}=\cdots$. Hence, in this case, $\left\{y_{n}\right\}$ is a 0 -Cauchy sequence in $(X, p)$.

Suppose now that $p\left(y_{n}, y_{n+1}\right)>0$ for each $n \in \mathbb{N}_{0}$.

\section{Claim 1.}

$$
\operatorname{diam} O_{f, g}\left(x_{0} ; \infty\right) \leq \frac{1}{1-\lambda} p\left(f x_{0}, f x_{1}\right)=\frac{1}{1-\lambda} p\left(y_{0}, y_{1}\right) .
$$

Indeed, let $1 \leq i, j \leq n$. Then

$$
\begin{aligned}
p\left(y_{i}, y_{j}\right) & =p\left(f x_{i}, f x_{j}\right) \\
& \leq \lambda \max \left\{p\left(g x_{i}, g x_{j}\right), p\left(g x_{i}, f x_{i}\right), p\left(g x_{j}, f x_{j}\right), p\left(g x_{i}, f x_{j}\right), p\left(g x_{j}, f x_{i}\right)\right\} \\
& =\lambda \max \left\{p\left(y_{i-1}, y_{j-1}\right), p\left(y_{i-1}, y_{i}\right), p\left(y_{j-1}, y_{j}\right), p\left(y_{i}, y_{j-1}\right), p\left(y_{j-1}, y_{i}\right)\right\} .
\end{aligned}
$$

Since the points $y_{i-1}, y_{i}, y_{j-1}, y_{j}$ belong to the set $O_{f, g}\left(x_{0} ; n\right)$, it follows that

$$
p\left(y_{i}, y_{j}\right) \leq \lambda \operatorname{diam} O_{f, g}\left(x_{0} ; n\right)<\operatorname{diam} O_{f, g}\left(x_{0} ; n\right) .
$$

Hence, there exists $k \leq n$ such that $\operatorname{diam} O_{f, g}\left(x_{0} ; n\right)=p\left(y_{0}, y_{k}\right)$. Since, by $\left(\mathrm{p}_{4}\right)$,

$$
\begin{aligned}
p\left(y_{0}, y_{k}\right) & \leq p\left(y_{0}, y_{1}\right)+p\left(y_{1}, y_{k}\right)-p\left(y_{1}, y_{1}\right) \\
& \leq p\left(y_{0}, y_{1}\right)+p\left(y_{1}, y_{k}\right)
\end{aligned}
$$


we have

$$
\operatorname{diam} O_{f, g}\left(x_{0} ; n\right) \leq p\left(y_{0}, y_{1}\right)+\lambda \operatorname{diam} O_{f, g}\left(x_{0} ; n\right),
$$

i.e., diam $O_{f, g}\left(x_{0} ; n\right) \leq \frac{1}{1-\lambda} p\left(y_{0}, y_{1}\right)$. Taking the supremum in this inequality, the proof of Claim 1 is obtained.

Claim 2. Let $m>n \geq 1$. Then

$$
p\left(y_{m}, y_{n}\right) \leq \frac{\lambda^{n}}{1-\lambda} p\left(y_{0}, y_{1}\right)
$$

Similarly as in (2.2), we have that

$$
p\left(y_{m}, y_{n}\right) \leq \lambda \max \left\{p\left(y_{m-1}, y_{n-1}\right), p\left(y_{m-1}, y_{m}\right), p\left(y_{n-1}, y_{n}\right), p\left(y_{m}, y_{n-1}\right), p\left(y_{n-1}, y_{m}\right)\right\} .
$$

Since $y_{m-1}, y_{m}, y_{n-1}, y_{n} \in O_{f, g}\left(x_{n-1} ; m-n+1\right)$, we have

$$
p\left(y_{m}, y_{n}\right) \leq \lambda O_{f, g}\left(x_{n-1} ; m-n+1\right)=\lambda p\left(y_{n-1}, y_{k_{1}}\right)
$$

for some $k_{1} \leq m$. Now, similarly,

$$
\begin{aligned}
p\left(y_{n-1}, y_{k_{1}}\right) & \leq \lambda \max \left\{p\left(y_{n-2}, y_{k_{1}-1}\right), p\left(y_{n-2}, y_{n-1}\right), p\left(y_{k_{1}-1}, y_{k_{1}}\right), p\left(y_{n-2}, y_{k_{1}}\right), p\left(y_{n-1}, y_{k_{1}-1}\right)\right\} \\
& \leq \lambda \operatorname{diam} O_{f, g}\left(x_{n-2} ; m-n+2\right),
\end{aligned}
$$

which, together with (2.4), gives

$$
p\left(y_{m}, y_{n}\right) \leq \lambda^{2} p\left(y_{n-2}, y_{k_{2}}\right)
$$

for some $k_{2} \leq m$. Continuing the process, we obtain that

$$
\begin{aligned}
p\left(y_{m}, y_{n}\right) & \leq \lambda^{n-1} \operatorname{diam} O_{f, g}\left(x_{1} ; m-1\right)=\lambda^{n-1} p\left(y_{1}, y_{k_{n-1}}\right) \\
& \leq \lambda^{n-1} \cdot \lambda \operatorname{diam} O_{f, g}\left(x_{0} ; m\right) \leq \frac{\lambda^{n}}{1-\lambda} p\left(y_{0}, y_{1}\right)
\end{aligned}
$$

and Claim 2 is proved.

It follows that $p\left(y_{m}, y_{n}\right) \rightarrow 0$ as $m, n \rightarrow \infty$, i.e., $\left\{y_{n}\right\}$ is a 0 -Cauchy sequence. Since $(X, p)$ is 0 -complete, there exists $v \in X, u=g v \in g X$ such that $y_{n}=g x_{n} \rightarrow u, n \rightarrow \infty$ (we have supposed that $g X$ is closed, and hence 0 -complete) and

$$
p(u, u)=\lim _{n \rightarrow \infty} p\left(y_{n}, u\right)=\lim _{m, n \rightarrow \infty} p\left(y_{m}, y_{n}\right)=0 .
$$

Now, we prove that also $f v=u$. We have

$$
\begin{aligned}
p(f v, u) & \leq p\left(f v, f x_{n}\right)+p\left(f x_{n}, u\right) \\
& \leq \lambda \max \left\{p\left(g v, g x_{n}\right), p(g v, f v), p\left(g x_{n}, f x_{n}\right), p\left(g v, f x_{n}\right), p\left(g x_{n}, f v\right)\right\}+p\left(y_{n}, u\right) \\
& =\lambda \max \left\{p\left(u, y_{n-1}\right), p(u, f v), p\left(y_{n-1}, y_{n}\right), p\left(u, y_{n}\right), p\left(y_{n-1}, f v\right)\right\}+p\left(y_{n}, u\right) .
\end{aligned}
$$


Since $p\left(u, y_{n-1}\right), p\left(y_{n-1}, y_{n}\right)$ and $p\left(u, y_{n}\right)$ tend to 0 as $n \rightarrow \infty$, and since

$$
p\left(y_{n-1}, f v\right) \leq p\left(y_{n-1}, u\right)+p(u, f v)-p(u, u)=p\left(y_{n-1}, u\right)+p(u, f v)
$$

if we suppose that $p(f v, u)>0$, we get a contradiction

$$
p(f v, u) \leq \lambda p(f v, u)
$$

Hence, $p(f v, u)=0$ and so $f v=u$.

Suppose that there exists $v_{1}, u_{1} \in X, u_{1} \neq u$ and $v_{1} \neq v$ such that $f v_{1}=g v_{1}=u_{1}$. Then

$$
\begin{aligned}
p\left(u, u_{1}\right) & =p\left(f v, f v_{1}\right) \\
& \leq \lambda \max \left\{p\left(g v, g v_{1}\right), p(g v, f v), p\left(g v_{1}, f v_{1}\right), p\left(g v, f v_{1}\right), p\left(g v_{1}, f v\right)\right\} \\
& =\lambda \max \left\{p\left(u, u_{1}\right), p(u, u), p\left(u_{1}, u_{1}\right), p\left(u, u_{1}\right), p\left(u_{1}, u\right)\right\} \\
& =\lambda p\left(u, u_{1}\right) \quad \text { by }\left(\mathrm{p}_{2}\right),
\end{aligned}
$$

which is possible only if $p\left(u, u_{1}\right)=0$, and hence $u=u_{1}$. Thus, we have proved that the point of coincidence of $f$ and $g$ is unique. By a well-known result, if $f$ and $g$ are weakly compatible, it follows that $f$ and $g$ have a unique common fixed point.

Remark 2 If $u$ is the unique common fixed point of $f$ and $g$ obtained as a limit of a Jungck sequence $\left\{y_{n}\right\}$ as in the previous proof, then the following error estimate holds

$$
p\left(y_{n}, u\right) \leq \frac{\lambda^{n}}{1-\lambda} p\left(y_{0}, y_{1}\right)
$$

Since $p$ is not continuous in general, this cannot be obtained directly from (2.3). Instead, notice that for $m>n$

$$
p\left(y_{n}, u\right) \leq p\left(y_{n}, y_{m}\right)+p\left(y_{m}, u\right) \leq \frac{\lambda^{n}}{1-\lambda} p\left(y_{0}, y_{1}\right)+p\left(y_{m}, u\right)
$$

Passing to the limit when $m \rightarrow \infty$, we get that

$$
p\left(y_{n}, u\right) \leq \frac{\lambda^{n}}{1-\lambda} p\left(y_{0}, y_{1}\right)+p(u, u)=\frac{\lambda^{n}}{1-\lambda} p\left(y_{0}, y_{1}\right)
$$

According to the well-known classification of Rhoades [17] (which obviously holds for partial as well as for standard metric), Theorem 1 implies several other (common) fixed point results, e.g., those of Banach, Kannan, Chatterjea, Bianchini, Hardy-Rogers and Zamfirescu. We state the last one which was obtained in [13, Theorem 4.2] in the special case $g=i_{X}$.

Corollary 1 Let $(X, p)$ be a 0-complete partial metric space, and let $f, g: X \rightarrow X$ be such that $f X \subset g X$ and one of these two subsets of $X$ is closed. Suppose that there exist $\alpha, \beta, \gamma$, with $0 \leq \alpha<1$ and $0 \leq \beta, \gamma<\frac{1}{2}$, such that for all $x, y \in X$, at least one of the following conditions hold: 
1. $p(f x, f y) \leq \alpha p(g x, g y)$;

2. $p(f x, f y) \leq \beta[p(g x, f x)+p(g y, f y)]$;

3. $p(f x, f y) \leq \gamma[p(g x, f y)+p(g y, f x)]$.

Then $f$ and $g$ have a unique point of coincidence $u \in X$. If, moreover, $f$ and $g$ are weakly compatible, then they have a unique common fixed point $u$ and $p(u, u)=0$ holds.

Proof Let the assumption of corollary hold and denote $\lambda=\max \{\alpha, 2 \beta, 2 \gamma\}$. Then for all $x, y \in X$, condition (2.1) of Theorem 1 is satisfied and the conclusion follows.

We give an easy example of a partial metric space, which is not a metric space, and a selfmap in it which is a quasicontraction and not a contraction.

Example 3 Consider the set $X=\{a, b, c\}$ and the function $p: X \times X \rightarrow \mathbb{R}$ given by $p(a, b)=$ $p(b, c)=1, p(a, c)=\frac{3}{2}, p(x, y)=p(y, x), p(a, a)=p(c, c)=\frac{1}{2}$ and $p(b, b)=0$. Obviously, $p$ is a partial metric on $X$, not being a metric (since $p(x, x) \neq 0$ for $x=a$ and $x=c$ ). Define a selfmap $f$ on $X$ by

$$
f:\left(\begin{array}{lll}
a & b & c \\
b & b & a
\end{array}\right) .
$$

Then $f$ is not a (Banach)-contraction since

$$
p(f c, f c)=p(a, a)=\frac{1}{2}=p(c, c)
$$

and there is no $\lambda \in[0,1)$ such that $p(f c, f c) \leq \lambda p(c, c)$. We will check that $f$ is an $i_{X^{-}}$ quasicontraction with $\lambda=\frac{2}{3}$. If $x, y \in\{a, b\}$, then $p(f x, f y)=p(b, b)=0$ and (2.1) trivially holds. Let, e.g., $y=c$; then we have the following three cases:

$$
\begin{aligned}
& p(f a, f c)=p(b, a)=1 \leq \frac{2}{3} \cdot \frac{3}{2}=\lambda \max \{p(a, c), p(a, f a), p(c, f c), p(a, f c), p(c, f a)\}, \\
& p(f b, f c)=p(b, a)=1 \leq \frac{2}{3} \cdot \frac{3}{2}=\lambda \max \{p(b, c), p(b, f b), p(c, f c), p(b, f c), p(c, f b)\}, \\
& p(f c, f c)=p(a, a)=\frac{1}{2}<\frac{2}{3} \cdot \frac{3}{2}=\lambda \max \{p(c, c), p(c, f c)\} .
\end{aligned}
$$

Thus, the conditions of Theorem 1 are satisfied and the existence of a common fixed point of $f$ and $i_{X}$ (which is $b$ ) follows. The same conclusion cannot be obtained by Banach-type fixed point results from $[15,21]$.

We present another example showing the use of Theorem 1. It also shows that there are situations when standard completeness of the $p$-metric as well as usual metric arguments cannot be used to obtain the existence of a fixed point.

Example 4 Let $X=[0,1] \cap \mathbb{Q}$ be equipped with the partial metric $p$ defined by $p(x, y)=$ $\max \{x, y\}$ for $x, y \in X$. Let $f, g: X \rightarrow X$ be given by

$$
f x=\frac{x^{2}}{1+x}, \quad x \in X \quad \text { and } \quad g=i_{X} .
$$


By Example 2, the space $(X, p)$ is 0 -complete (but not complete). Take $\lambda=\frac{1}{2}$. The contractive condition (2.1) for (say) $x \geq y$ takes the form

$$
\begin{aligned}
p(f x, f y) & =\max \left\{\frac{x^{2}}{1+x}, \frac{y^{2}}{1+y}\right\}=\frac{x^{2}}{1+x} \\
& \leq \frac{1}{2} \max \left\{p(x, y), p\left(x, \frac{x^{2}}{1+x}\right), p\left(y, \frac{y^{2}}{1+y}\right), p\left(x, \frac{y^{2}}{1+y}\right), p\left(y, \frac{x^{2}}{1+x}\right)\right\} \\
& =\frac{1}{2} \max \left\{x, x, y, x, \max \left\{y, \frac{x^{2}}{1+x}\right\}\right\}=\frac{1}{2} x,
\end{aligned}
$$

and it is satisfied for all $x, y \in X$ since $0 \leq x \leq 1$. Hence, all the conditions of Theorem 1 are satisfied and $f$ and $g$ have a unique common fixed point $(u=0)$.

Since $(X, p)$ is not complete, nor is the space $(X, d)$, where $d=p^{s}$ is the Euclidean metric, the existence of a (common) fixed point cannot be deduced using known results.

\section{Mappings with a contractive iterate}

In this section, we prove a version of Sehgal-Guseman theorem ([10, 20], see also [17]) for 0 -complete partial metric spaces.

Theorem 2 Let $(X, p)$ be a 0-complete partial metric space and let $f: X \rightarrow X$. Suppose that there exists $\lambda \in[0,1)$ such that for each $x \in X$ there is $k(x) \in \mathbb{N}$ satisfying

$$
p\left(f^{k(x)} x, f^{k(x)} y\right) \leq \lambda p(x, y)
$$

for every $y \in X$. Then $f$ has a unique fixed point $z \in X$. Moreover, $p(z, z)=0$ and every Picard sequence $\left\{f^{n} x\right\}$ converges to $z$.

Proof We first note that, similarly as in the metric case, the following can be proved:

Under the assumptions of the theorem,

$$
R(x)=\sup _{n \in \mathbb{N}} p\left(x, f^{n} x\right) \leq \frac{1}{1-\lambda} \max \left\{p\left(x, f^{j} x\right): 1 \leq j \leq k(x)\right\}
$$

In particular, $\sup _{n \in \mathbb{N}} p\left(x, f^{n} x\right)$ is a finite real number for each $x \in X$.

Let $x_{0} \in X$ be arbitrary. Construct the sequence $\left\{x_{n}\right\}$ in the following way:

$$
x_{1}=f^{k\left(x_{0}\right)} x_{0}, \quad x_{2}=f^{k\left(x_{1}\right)} x_{1}, \quad \ldots, \quad x_{n}=f^{k\left(x_{n-1}\right)} x_{n-1}, \quad \ldots
$$

We will prove that this is a 0 -Cauchy sequence.

If $p\left(x_{n-1}, x_{n}\right)=0$ for some $n$, then it easily follows that this sequence is eventually constant, and hence a 0 -Cauchy one. Suppose further that $p\left(x_{n-1}, x_{n}\right)>0$ for each $n$. Condition (3.1) implies that

$$
\begin{aligned}
p\left(x_{n}, x_{n+1}\right) & =p\left(f^{k\left(x_{n-1}\right)} x_{n-1}, f^{k\left(x_{n}\right)} x_{n}\right)=p\left(f^{k\left(x_{n-1}\right)} x_{n-1}, f^{k\left(x_{n}\right)} f^{k\left(x_{n-1}\right)} x_{n-1}\right) \\
& =p\left(f^{k\left(x_{n-1}\right)} x_{n-1}, f^{k\left(x_{n-1}\right)} f^{k\left(x_{n}\right)} x_{n-1}\right) \leq \lambda p\left(x_{n-1}, f^{k\left(x_{n}\right)} x_{n-1}\right) .
\end{aligned}
$$


Repeating this procedure $n$ times, we get that

$$
p\left(x_{n}, x_{n+1}\right) \leq \lambda^{n} p\left(x_{0}, f^{k\left(x_{n}\right)} x_{0}\right) \leq \lambda^{n} R\left(x_{0}\right) \rightarrow 0
$$

as $n \rightarrow \infty$ since $R\left(x_{0}\right)<+\infty$ by (3.2).

Now, using standard arguments, it is easy to show that $p\left(x_{m}, x_{n}\right) \rightarrow 0$ as $m, n \rightarrow \infty$. Hence, $\left\{x_{n}\right\}$ is a 0 -Cauchy sequence. Since the space $(X, p)$ is 0 -complete, there exists $z \in X$ satisfying $p\left(x_{n}, z\right) \rightarrow 0, n \rightarrow \infty$, with $p(z, z)=0$.

It follows from condition (3.1) that

$$
p\left(f^{k(z)} z, f^{k(z)} x_{n}\right) \leq \lambda p\left(z, x_{n}\right) \rightarrow \lambda p(z, z)=0
$$

as $n \rightarrow \infty$. Hence, $f^{k(z)} x_{n} \rightarrow f^{k(z)} z$ in $(X, p)$. Further we have

$$
\begin{aligned}
p\left(f^{k(z)} z, z\right) & \leq p\left(f^{k(z)} z, f^{k(z)} x_{n}\right)+p\left(f^{k(z)} x_{n}, z\right)-p\left(f^{k(z)} x_{n}, f^{k(z)} x_{n}\right) \\
& \leq p\left(f^{k(z)} z, f^{k(z)} x_{n}\right)+p\left(f^{k(z)} x_{n}, z\right) \\
& \leq p\left(f^{k(z)} z, f^{k(z)} x_{n}\right)+p\left(f^{k(z)} x_{n}, x_{n}\right)+p\left(x_{n}, z\right)-p\left(x_{n}, x_{n}\right) \\
& \leq p\left(f^{k(z)} z, f^{k(z)} x_{n}\right)+p\left(f^{k(z)} x_{n}, x_{n}\right)+p\left(x_{n}, z\right) .
\end{aligned}
$$

The first and third summand on the right-hand side tend to 0 when $n \rightarrow \infty$. For the second summand we have

$$
\begin{aligned}
p\left(f^{k(z)} x_{n}, x_{n}\right) & =p\left(f^{k(z)} f^{k\left(x_{n-1}\right)} x_{n-1}, f^{k\left(x_{n-1}\right)} x_{n-1}\right) \\
& =p\left(f^{k\left(x_{n-1}\right)} f^{k(z)} x_{n-1}, f^{k\left(x_{n-1}\right)} x_{n-1}\right) \\
& \leq \lambda p\left(f^{k(z)} x_{n-1}, x_{n-1}\right) \leq \cdots \leq \lambda^{n} R\left(x_{0}\right) \\
& \rightarrow 0
\end{aligned}
$$

as $n \rightarrow \infty$. Thus, $p\left(f^{k(z)} z, z\right)=0$ and so $f^{k(z)} z=z$. If $z$ and $u$ were two distinct fixed points of $f^{k(z)}$, then (3.1) would imply that

$$
p(z, u)=p\left(f^{k(z)} z, f^{k(z)} u\right) \leq \lambda p(z, u)<p(z, u)
$$

a contradiction.

Now, we easily get that

$$
f^{k(z)} f z=f^{k(z)} z=f z
$$

and it must be $f z=z$, i.e., $z$ is a (unique) fixed point of $f$.

In order to prove that $f$ is a Picard operator, let $x \in X$ be arbitrary and $\left\{f^{n} x\right\}$ be the corresponding Picard sequence. Each $n \in \mathbb{N}, n>k(z)$ can be uniquely written in the form

$$
n=m \cdot k(z)+q
$$


and $m \rightarrow \infty$ when $n \rightarrow \infty$. Let $z$ be the (unique) fixed point of $f$ whose existence has just been proved. Then

$$
\begin{aligned}
p\left(z, f^{n} x\right) & =p\left(f^{k(z)} z, f^{k(z)} f^{(m-1) k(z)+q} x\right) \leq \lambda p\left(z, f^{(m-1) k(z)+q} x\right) \\
& =\lambda p\left(f^{k(z)} z, f^{k(z)} f^{(m-2) k(z)+q} x\right) \leq \lambda^{2} p\left(z, f^{(m-2) k(z)+q} x\right) \\
& \leq \cdots \leq \lambda^{m} p\left(z, f^{q} x\right) \leq \lambda^{m}\left(p(z, x)+p\left(x, f^{q} x\right)\right) \leq \lambda^{m}(p(z, x)+R(x)) .
\end{aligned}
$$

Now, using what was previously proved, we obtain that $p\left(z, f^{n} x\right) \rightarrow 0=p(z, z)$ and $f$ is a Picard operator.

Example 5 Let $(X, p)$ and $f$ be as in Example 3. We have seen that $f$ is not a contraction in the partial metric space $(X, p)$. However, $f^{2}:\left(\begin{array}{lll}a & b & c \\ b & b & b\end{array}\right)$ and $f$ satisfies condition (3.1) of Theorem 2 with $k(x)=2$ for each $x \in X$ since $p\left(f^{2} x, f^{2} y\right)=p(b, b)=0$ for each $y \in X$. As we have seen, $f$ has a unique fixed point $b$.

\section{Partial metric version of a theorem of Rhoades}

The following theorem is a partial metric version of an interesting result obtained by B. E. Rhoades [17, Theorem 4].

Theorem 3 Let $(X, p)$ be a 0-complete partial metric space. Let $f, g: X \rightarrow X$ be two mappings such that $f X \subset g X$ and one of these subsets of $(X, p)$ is closed. Suppose that there exist decreasing functions $\alpha_{i}:[0,+\infty) \rightarrow[0,1), i=1, \ldots, 5$, such that $\sum_{i=1}^{5} \alpha_{i}(t)<1$ for each $t \in[0,+\infty)$ and satisfying

$$
\begin{aligned}
p(f x, f y) \leq & \alpha_{1}(p(g x, g y)) p(g x, g y)+\alpha_{2}(p(g x, g y)) p(g x, f x)+\alpha_{3}(p(g x, g y)) p(g y, f y) \\
& +\alpha_{4}(p(g x, g y)) p(f y, g x)+\alpha_{5}(p(g x, g y)) p(f x, g y)
\end{aligned}
$$

for all $x, y \in X$. Then $f$ and $g$ have a unique point of coincidence. If, moreover, $f$ and $g$ are weakly compatible, then $f$ and $g$ have a unique common fixed point, say $z$, with $p(z, z)=$ $p(f z, f z)=p(g z, g z)=0$.

Proof Suppose, e.g., that $g X$ is closed. Take an arbitrary $x_{0} \in X$ and, using that $f X \subset g X$, construct a Jungck sequence $\left\{y_{n}\right\}$ defined by $y_{n}=f x_{n}=g x_{n+1}, n=0,1,2, \ldots$. Let us prove that this is a 0 -Cauchy sequence. If $p\left(y_{n}, y_{n-1}\right)=0$ for some $n$, then as in the proof of Theorem 1 , one proves that the sequence $\left\{y_{n}\right\}$ becomes eventually constant, and thus convergent.

Suppose that $p\left(y_{n}, y_{n-1}\right)>0$ for each $n \in \mathbb{N}$. Using (4.1) (and putting temporarily $\alpha_{i}=$ $\left.\alpha_{i}\left(p\left(y_{n-1}, y_{n}\right)\right), i=1, \ldots, 5\right)$, we obtain that

$$
\begin{aligned}
p\left(y_{n}, y_{n+1}\right)= & p\left(f x_{n}, f x_{n+1}\right) \\
\leq & \alpha_{1} p\left(y_{n-1}, y_{n}\right)+\alpha_{2} p\left(y_{n-1}, y_{n}\right)+\alpha_{3} p\left(y_{n}, y_{n+1}\right) \\
& +\alpha_{4} p\left(y_{n+1}, y_{n-1}\right)+\alpha_{5} p\left(y_{n}, y_{n}\right) \\
\leq & \alpha_{1} p\left(y_{n-1}, y_{n}\right)+\alpha_{2} p\left(y_{n-1}, y_{n}\right)+\alpha_{3} p\left(y_{n}, y_{n+1}\right) \\
& +\alpha_{4}\left[p\left(y_{n-1}, y_{n}\right)+p\left(y_{n}, y_{n+1}\right)-p\left(y_{n}, y_{n}\right)\right]+\alpha_{5} p\left(y_{n}, y_{n}\right),
\end{aligned}
$$


for each $n \in \mathbb{N}$. Also,

$$
\begin{aligned}
p\left(y_{n+1}, y_{n}\right)= & p\left(f x_{n+1}, f x_{n}\right) \\
\leq & \alpha_{1} p\left(y_{n-1}, y_{n}\right)+\alpha_{2} p\left(y_{n}, y_{n+1}\right)+\alpha_{3} p\left(y_{n-1}, y_{n}\right)+\alpha_{4} p\left(y_{n}, y_{n}\right)+\alpha_{5} p\left(y_{n-1}, y_{n+1}\right) \\
\leq & \alpha_{1} p\left(y_{n-1}, y_{n}\right)+\alpha_{2} p\left(y_{n}, y_{n+1}\right)+\alpha_{3} p\left(y_{n-1}, y_{n}\right) \\
& +\alpha_{4} p\left(y_{n}, y_{n}\right)+\alpha_{5}\left[p\left(y_{n-1}, y_{n}\right)+p\left(y_{n}, y_{n+1}\right)-p\left(y_{n}, y_{n}\right)\right] .
\end{aligned}
$$

Adding up the last two relations, we obtain

$$
p\left(y_{n}, y_{n+1}\right) \leq \beta\left(p\left(y_{n-1}, y_{n}\right)\right) p\left(y_{n-1}, y_{n}\right)
$$

where

$$
\beta(t)=\frac{2 \alpha_{1}(t)+\alpha_{2}(t)+\alpha_{3}(t)+\alpha_{4}(t)+\alpha_{5}(t)}{2-\left(\alpha_{2}(t)+\alpha_{3}(t)+\alpha_{4}(t)+\alpha_{5}(t)\right)} .
$$

It is easy to see that monotonicity of all $\alpha_{i}$ 's implies that $\beta$ is also a decreasing function and that $0<\beta(t)<1$ for each $t \in[0,+\infty)$. In particular, $p\left(y_{n}, y_{n+1}\right)<p\left(y_{n-1}, y_{n}\right)$ and so the sequence $\left\{p\left(y_{n}, y_{n+1}\right)\right\}$ is strictly decreasing (and bounded from below). It follows that there exists $\lim _{n \rightarrow \infty} p\left(y_{n}, y_{n+1}\right)=r$ and $0 \leq r \leq p\left(y_{n}, y_{n+1}\right)$ for each $n$. Then $1>\beta(r)>\beta\left(p\left(y_{n}, y_{n+1}\right)\right)$ for each $n$, and hence

$$
p\left(y_{n}, y_{n+1}\right) \leq \beta(r) p\left(y_{n-1}, y_{n}\right) \leq(\beta(r))^{2} p\left(y_{n-2}, y_{n-1}\right) \leq \cdots \leq(\beta(r))^{n} p\left(y_{0}, y_{1}\right),
$$

where $\beta(r) \in[0,1)$ is fixed.

Now we prove that $\left\{y_{n}\right\}$ is a 0 -Cauchy sequence in the usual way: for $m>n$ it is

$$
\begin{aligned}
p\left(y_{n}, y_{m}\right) & \leq p\left(y_{n}, y_{n+1}\right)+\cdots+p\left(y_{m-1}, y_{m}\right) \\
& \leq\left((\beta(r))^{n}+\cdots+(\beta(r))^{m-1}\right) p\left(y_{0}, y_{1}\right) \\
& \leq \frac{(\beta(r))^{n}}{1-\beta(r)} p\left(y_{0}, y_{1}\right) \rightarrow 0 \quad \text { as } n \rightarrow \infty .
\end{aligned}
$$

It follows that $\left\{y_{n}\right\}$ is a 0 -Cauchy sequence. Since this space is 0 -complete, there exists $z \in g X$ (i.e., $z=g u, u \in X$ ) such that $y_{n}=g x_{n+1} \rightarrow z, n \rightarrow \infty$ (we have supposed that $g X$ is closed, and hence 0 -complete) and $p(z, z)=0$. We will prove that $f u=g u$.

Put $x=x_{n}, y=u$ in the contractive condition. We obtain (writing temporarily $\alpha_{i}=$ $\left.\alpha_{i}\left(p\left(x_{n}, u\right)\right)\right)$ that

$$
\begin{aligned}
p(g u, f u) \leq & p\left(g u, g x_{n+1}\right)+p\left(f x_{n}, f u\right) \\
\leq & p\left(g u, g x_{n+1}\right)+\alpha_{1} p\left(g x_{n}, g u\right)+\alpha_{2} p\left(g x_{n}, f x_{n}\right) \\
& +\alpha_{3} p(g u, f u)+\alpha_{4} p\left(f u, g x_{n}\right)+\alpha_{5} p\left(f x_{n}, g u\right) \\
\leq & p\left(g u, g x_{n+1}\right)+\alpha_{1} p\left(g x_{n}, g u\right)+\left(\alpha_{2}+\alpha_{4}\right) p\left(g x_{n}, f x_{n}\right) \\
& +\alpha_{3} p(g u, f u)+\alpha_{4} p\left(f u, f x_{n}\right)+\alpha_{5} p\left(f x_{n}, g u\right)
\end{aligned}
$$




$$
\begin{aligned}
\leq & p\left(g u, g x_{n+1}\right)+\alpha_{1} p\left(g x_{n}, g u\right)+\left(\alpha_{2}+\alpha_{4}\right) p\left(g x_{n}, f x_{n}\right) \\
& +\left(\alpha_{3}+\alpha_{4}\right) p(g u, f u)+\left(\alpha_{4}+\alpha_{5}\right) p\left(f x_{n}, g u\right)
\end{aligned}
$$

Taking into account that all $\alpha_{i}$ 's are bounded in $[0,1)$, passing to the limit in the last inequality, we obtain that

$$
p(g u, f u) \leq 0+\alpha_{1} \cdot 0+\left(\alpha_{2}+\alpha_{4}\right) \cdot 0+\left(\alpha_{3}+\alpha_{4}\right) p(g u, f u)+\left(\alpha_{4}+\alpha_{5}\right) \cdot 0,
$$

i.e., $p(g u, f u) \leq\left(\alpha_{3}+\alpha_{4}\right) p(g u, f u)$. Since $\alpha_{3}+\alpha_{4}<1$, it follows that $p(f u, g u)=0, g u=f u=z$, and $f$ and $g$ have a point of coincidence $z$.

Suppose that $z_{1}=f u_{1}=g u_{1}$ is another point of coincidence for $f$ and $g$. Then (4.1) implies that $p\left(z_{1}, z_{1}\right)=0$ and also that

$$
\begin{aligned}
p\left(z, z_{1}\right) & =p\left(f u, f u_{1}\right) \\
& \leq \alpha_{1} p\left(g u, g u_{1}\right)+\alpha_{2} p(g u, f u)+\alpha_{3} p\left(g u_{1}, f u_{1}\right)+\alpha_{4} p\left(f u_{1}, g u\right)+\alpha_{5} p\left(f u, g u_{1}\right) \\
& =\alpha_{1} p\left(z, z_{1}\right)+\alpha_{2} \cdot 0+\alpha_{3} \cdot 0+\alpha_{4} p\left(z_{1}, z\right)+\alpha_{5} p\left(z, z_{1}\right) \\
& =\left(\alpha_{1}+\alpha_{4}+\alpha_{5}\right) p\left(z, z_{1}\right) .
\end{aligned}
$$

Since $\alpha_{1}+\alpha_{4}+\alpha_{5}<1$, the last relation is possible only if $p\left(z, z_{1}\right)=0$ and hence $z=z_{1}$. So, the point of coincidence is unique.

The proof is similar if the subset $f X$ of $X$ is closed.

By a well-known result, if $f$ and $g$ are weakly compatible, it follows that $f$ and $g$ have a unique common fixed point.

Remark 3 Taking $(X, p)$ to be a standard metric space and $g=i_{X}$, we obtain a shorter proof of [17, Theorem 4].

Remark 4 Taking appropriate choices of $f, g$ and $\alpha_{i}, i=1, \ldots, 5$ in Theorem 3, one can easily get the results of Reich [17, (7), (8)], Hardy-Rogers [17, (18)] and Ćirić [17, (21)] in the setting of partial metric spaces.

Remark 5 We finally note that, in a similar way, several other fixed point results in partial metric spaces obtained recently (e.g., [1, Theorem 8], [2, Theorem 5], [3, Theorems 1 and 2], [6, Theorem 2.1], [14, Theorem 5], [19, Theorems 3 and 4]) can be proved with a (strictly) weaker assumption of 0 -completeness instead of completeness.

\section{Competing interests}

The authors declare that they have no competing interests.

\section{Authors' contributions}

All authors contributed equally and significantly in writing this paper. All authors read and approved the final manuscript.

\section{Author details}

1 'Dipartimento di Matematica ed Applicazioni, Università degli Studi di Palermo, Via Archirafi 34, Palermo, 90123, Italy. ${ }^{2}$ Faculty of Mathematics, University of Belgrade, Studentski trg 16, Beograd, 11000, Serbia. ${ }^{3}$ Department of Mathematics, Disha Institute of Management and Technology, Satya Vihar, Vidhansabha-Chandrakhuri Marg, Mandir Hasaud, Raipur (Chhattisgarh) 492101, India. ${ }^{4}$ Faculty of Mechanical Engineering, University of Belgrade, Kraljice Marije 16, Beograd, 11120, Serbia. 


\section{Acknowledgement}

The second and the fourth author are thankful to the Ministry of Science and Technological Development of Serbia.

\section{Received: 17 February 2012 Accepted: 2 July 2012 Published: 19 July 2012}

\section{References}

1. Abdeljawad, T: Fixed points of generalized weakly contractive mappings in partial metric spaces. Math. Comput. Model. 54, 2923-2927 (2011)

2. Abdeljawad, T, Karapinar, E, Taş, K: Existence and uniqueness of a common fixed point on partial metric spaces. Appl. Math. Lett. 24, 1900-1904 (2011)

3. Altun, I: Partial metric spaces. Am. Math. Mon. 116, 708-718 (2009)

4. Bukatin, M, Kopperman, R, Matthews, S, Pajoohesh, H: Partial metric spaces. Am. Math. Mon. 116, 708-718 (2009)

5. Cirić, LB: A generalization of Banach's contraction principle. Proc. Am. Math. Soc. 45, 267-273 (1974)

6. Ćirić, L, Samet, B, Aydi, H, Vetro, C: Common fixed points of generalized contractions on partial metric spaces and an application. Appl. Math. Comput. 218, 2398-2406 (2011)

7. Das, KM, Naik, KV: Common fixed point theorems for commuting maps on metric spaces. Proc. Am. Math. Soc. 77, 369-373 (1979)

8. Đukić, D, Kadelburg, Z, Radenović, S: Fixed points of Geraghty-type mappings in various generalized metric spaces. Abstr. Appl. Anal. 2011, Article ID 561245 (2011). doi:10.1155/2011/561245

9. Escardo, MH: Pcf extended with real numbers. Theor. Comput. Sci. 162, 79-115 (1996)

10. Guseman Jr., LR: Fixed point mappings for with a contractive iterate at a point. Proc. Am. Math. Soc. 26, 615-618 (1970)

11. Heckmann, R: Approximation of metric spaces by partial metric spaces. Appl. Categ. Struct. 7, 71-83 (1999)

12. Ilić, D, Pavlović, V, Rakočević, V: Some new extensions of Banach's contraction principle to partial metric spaces. Appl. Math. Lett. 24, 1326-1330 (2011)

13. Ilić, D, Pavlović, V, Rakočević, V: Extensions of Zamfirescu theorem to partial metric spaces. Math. Comput. Model. 55, 801-809 (2012)

14. Karapinar, E: Fixed point theorems for operators on partial metric spaces. Appl. Math. Lett. 24, 1894-1899 (2011)

15. Matthews, SG: Partial metric topology. In: Proc. 8th Summer Conference on General Topology and Applications. Ann. New York Acad. Sci., vol. 728, pp. 183-197 (1994)

16. Oltra, S, Valero, O: Banach's fixed point theorem for partial metric spaces. Rend. Ist. Mat. Univ. Trieste 36, 17-26 (2004)

17. Rhoades, BE: A comparison of various definitions of contractive mappings. Trans. Am. Math. Soc. 336, $257-290$ (1977)

18. Romaguera, S: A Kirk type characterization of completeness for partial metric spaces. Fixed Point Theory Appl. 2010, Article ID 493298 (2010). doi:10.1155/2010/493298

19. Romaguera, S: Fixed point theorems for generalized contractions on partial metric spaces. Topol. Appl. 159, 194-199 (2012)

20. Sehgal, VM: A fixed point theorem for mappings with a contractive iterate. Proc. Am. Math. Soc. 23, 631-634 (1969)

21. Valero, O: On Banach fixed point theorems for partial metric spaces. Appl. Gen. Topol. 6, 229-240 (2005)

22. Paesano, D, Vetro, P: Suzuki's type characterizations of completeness for partial metric spaces and fixed points for partially ordered metric spaces. Topol. Appl. 159, 911-920 (2012)

doi:10.1186/1687-1812-2012-113

Cite this article as: di Bari et al.: Common fixed points of $g$-quasicontractions and related mappings in 0-complete partial metric spaces. Fixed Point Theory and Applications 2012 2012:113.

\section{Submit your manuscript to a SpringerOpen ${ }^{\circ}$ journal and benefit from:}

- Convenient online submission

- Rigorous peer review

- Immediate publication on acceptance

- Open access: articles freely available online

- High visibility within the field

- Retaining the copyright to your article 